\title{
Transferência de biotecnologia ${ }^{1}$
}

\author{
André C. R. Fontes ${ }^{2}$
}

\section{Resumo}

$\mathrm{O}$ artigo trata da transferência de Biotecnologia em um confronto com a transferência geral de tecnologia e do reconhecimento do regime das obrigações de meio e resultado nos contratos que tenham como objeto tecnologia a ser cedida.

Palavras-chave: Contrato; Tecnologia; Obrigação; Meio; Resultado.

\section{Abstract}

This article deals with Biotechnology transfer in comparison to general technology transfer as well as it discusses the acknowledgement of the rule of obligations in kind and in result for contracts which purpose is cession of technology.

Keywords: Contract; Technology; Obligation; Kind; Result.

\footnotetext{
${ }^{1}$ Texto extraído de pesquisa realizada pelo autor na Faculdade de Direito da Universidade de São Paulo, sob a supervisão do Professor Doutor Newton Silveira, a quem, igualmente, este artigo é dedicado.

${ }^{2}$ Doutor em Direito pela Universidade do Estado do Rio de Janeiro (UERJ), Doutor em Ciências Ambientais e Florestais pela Universidade Federal Rural do Rio de Janeiro (UFRRJ), Professor na Universidade do Estado do Rio de Janeiro (Uni-Rio) e Desembargador do Tribunal Regional Federal da $2^{\mathrm{a}}$ Região (Rio de Janeiro e Espírito Santo).
} 


\section{PARTE 1 - O CONHECIMENTO BIOTECNOLÓGICO}

\subsection{A Biotecnologia}

\subsubsection{Noção}

Toda aplicação tecnológica dirigida à Biologia é uma tecnologia biológica e dessa locução se origina o termo Biotecnologia. E todos os especialistas que cuidam da Biotecnologia registram e desenvolvem, ora mais ora menos, detidamente, o seu objeto material. Fazem-no com o esclarecimento de que não se dá ênfase ao tema da categorização científica e se limitam a construir o seu conteúdo ou o campo no qual será aplicada.

Nas formas embrionárias da Filosofia da Ciência, mas sem resultados conclusivos, muito se tem debatido, ainda que em literatura especializada, a propósito da caracterização científica da Biotecnologia. Pelos efeitos que proporciona e pelo fato de ostentar algo diferente, em comparação com as demais formas de conhecimento, reinam certas dúvidas entre os especialistas. A singularidade cresce pelo impulso científico que causa e pelo impacto na vida moderna. Não é a Biotecnologia, entretanto, um ramo novo da Ciência. E o fato de os autores não se harmonizarem na sua configuração, levando a explicações teóricas que avizinham-se até mesmo das contradições, outra coisa não fazem senão estenderem o campo da imaginação. Mais recentemente encontra-se uma orientação que, mesmo sem o apoio uniforme dos escritores, merece maior destaque: a de que não é a Biotecnologia outra coisa que um conjunto de tecnologias amalgamadas. Não deve ser negada, entretanto, a importância prática dessa discussão, especialmente se se considerar a finalidade geral e integral da ciência consistente em ampliar de modo sucessivo a atividade racional do ser humano e em liberá-lo das forças espontâneas mediante a passagem dos processos quase irracionais da natureza em processos racionais. 
Em um sentido amplo, e atendendo à sua linha de evolução conclusiva, pode-se definir a Biotecnologia como o uso de organismos vivos ou partes deles (estruturas subcelulares ou moléculas) para a produção de bens e serviços. Embora alicerçada em dupla perspectiva reducionista (organismos vivos ou partes deles e produção de bens e serviços) engloba essa definição um conjunto de atividades que o homem desenvolve há milhares de anos, como seria exemplo a produção de alimentos fermentados. E é nessa linha de raciocínio que se considera a Biotecnologia moderna como aquela que, contemplando a definição em dupla perspectiva, faz uso da informação genética, incorporando técnicas de ADN (ácido desoxirribonucleico, mais conhecido como DNA) recombinante.

Se com o passar do tempo e com o desenvolvimento das tecnologias biológicas tornou-se a Biotecnologia, em sua pureza, uma disciplina de intensivo avanço científico, com uma interdisciplinaridade sem paralelo com outras disciplinas, e associada a fortes vínculos de complementariedade com outras tecnologias já existentes, não seria absurdo informar que a civilização do nosso tempo encontraria verdadeira estagnação na subsistência de toda gente se a complexidade de seus arquétipos encontrasse alguma alteração. Conquanto seja ressaltada essa especificidade, uma função econômica foi determinada entre as empresas que com ela se vinculam: é a constante necessidade de inovação, lançamento de novos produtos e desenvolvimento de tecnologia. Englobadas essas características às de necessidade do mundo atual, retomam elas as premissas de que, sem a Biotecnologia, a vida individual regrediria ao limitar a atividade do homem aos seus momentos primários. Paralelamente à função econômica, aponta-se uma outra civilizadora em si, e, porque não dizer, de cunho educativo. Aproxima ela os homens e abate as diferenças. Enquanto o indivíduo admite a possibilidade de obter o necessário pelas transformações do mundo, pôde apurar o seu senso de escassez, que somente veio a ganhar maior amplitude quando os geógrafos e estatísticos convenceram a todos a observar os limites dos insumos 
naturais no esforço constante do progresso e na consecução de uma era marcada pela harmonia alimentar, de saúde e meio ambiente.

Constitui, portanto, a Biotecnologia, em si mesma, um motivo de esforço que deve orientar as atividades de pesquisa e desenvolvimento para descobrir novas aplicações e gerar sinergias com outras áreas, não obstante os desafios dos novos problemas e os custos das tecnologias. É preciso acautelar-se, entretanto, contra as incertezas e riscos das primeiras fases de desenvolvimento de uma tecnologia biológica, pelo eventual insucesso ou mesmo malogro de uma pesquisa. Todo vigor de uma área em que se almeja uma enorme variedade de resultados pode restar em vão se esses resultados tardam a vir ou não alcancem os efeitos esperados.

\subsubsection{A tecnologia biotecnológica}

Sem repetirmos aqui o que já foi exposto nos lugares indicados, devese referir, ainda que bem sucintamente, ao uso dos termos e de algumas definições basilares. E assim se faz pelos recentes avanços das invenções biotecnológicas. Mesmo que guardem correspondência com os termos tradicionalmente usados, o melhor a fazer é repisar o assunto com uma série de aclarações e a definir termos e conceitos.

Em sua etimologia de origem grega (de bios, vida), a Biotecnologia se refere, grossomodo, às tecnologias que utilizam organismos vivos. Se a premissa anterior é um ponto pacífico, talvez pela sua generalidade, uma definição mais precisa não encontraria tamanha uniformidade.

A Comissão de especialistas em invenções biotecnológicas e propriedade industrial da Organização Mundial da Propriedade Intelectual, em sua sessão de fevereiro de 1986, em Genebra, assim se manifestou sobre o significado da Biotecnologia: "biotecnologia engloba todas as técnicas que utilizam organismos vivos, em particular, animais, plantas e micro-organismos, ou qualquer tipo de material biológico que pode ser 
assimilado aos micro-organismos ou partes dos mesmos, para provocar neles mudanças orgânicas".

Considerando a situação desta pesquisa, na qual a palavra técnica é determinante, deve ser lembrado que se faz referência basicamente à genética, à microbiologia, à biologia e à bioquímica, e seus campos de aplicação se encontram diretamente relacionados com a agricultura, a química, a indústria farmacêutica, a saúde, a produção de alimentos e a conservação do meio ambiente.

Outra definição clara e detalhada é a proposta pelo Escritório de avaliação de tecnologia do Congresso dos Estados Unidos da América, em seu segundo informe de 1984, segundo a qual "a biotecnologia compreende todas as técnicas que utilizam os organismos vivos (ou parte desses organismos) para fabricar ou modificar produtos, para melhorar as plantas ou os animais, ou desenvolver micro-organismos para usos particulares".

Os organismos vivos utilizados na Biotecnologia são:

a) Os organismos em seu estado natural;

b) Os organismos obtidos por meios convencionais de seleção, cruzamento ou mutação;

c) Os organismos modificados por novas técnicas.

São exemplo dos organismos em seu estado natural, os microorganismos usados em processos de fermentação. Exemplo de organismos obtidos por meios convencionais de seleção são os procedimentos essencialmente biológicos. E finalmente são exemplos de organismo modificados por novas técnicas aqueles como a engenharia genética ou técnica de fusão celular.

Pode-se classificar, então, a Biotecnologia em quatro grupos:

1) Os organismos vivos; 
2) Os procedimentos para obtenção de organismos vivos;

3) Os procedimentos que utilizam micro-organismos novos e conhecidos;

4) Os produtos obtidos com esses procedimentos.

Por organismos vivos se entendem os animais, as plantas e os microorganismos, definindo-se como micro-organismos todos os seres microscópicos vivos, que sejam de natural ocorrência ou obtidos mediante métodos convencionais ou novas técnicas. E dentro dos micro-organismos se encontram incluídos, dentre outros, o vírus, as bactérias, os fundos e as algas.

Os procedimentos para a obtenção de organismos vivos podem ser divididos em duas classes:

1) Os métodos convencionais;

2) Os métodos não-convencionais ou novos.

São convencionais os métodos de seleção, cruzamento e mutação. São não-convencionais ou novos a engenharia genética ou a técnica de fusão celular. A diferença essencial entre os denominados métodos convencionais ou tradicionais e os métodos não-convencionais ou novos reside na possibilidade desses últimos, mediante manipulação de material hereditário, ultrapassarem as barreiras biológicas preexistentes, como seria, por exemplo, as incompatibilidades entre as espécies. Deve ser ressalvado que esses métodos não são fins em si mesmos, mas destinados à obtenção de produtos úteis, mediante esses organismos vivos ou cultivos de células.

Demais disso, não é demasiado lembrar que a técnica de seleção foi a primeira que se usou para melhorar as plantas e animais. É dessa forma que, ao longo do tempo, foram introduzidas técnicas mais elaboradas, como seriam o cruzamento de diferentes genótipos, o cruzamento de pedigrees e as mutações, que consistem em usar meios físicos ou químicos 
para provocar mudanças em um genótipo. E é possível modificar os genes das plantas, dos animais e dos micro-organismos mediante a introdução de material hereditário modificado artificialmente. A técnica de mutação também é utilizada para obter novos micro-organismos. E isso ocorre com a aplicação de métodos novos ou não convencionais para obter organismos vivos, e é dentro desses métodos que se destacam a engenharia genética e a técnica da fusão celular.

Entende-se por engenharia genética a técnica do ADN recombinado, e consiste em isolar um gene de seu contexto natural e usá-lo de maneira tal que, em nível biológico, se possa obter uma quantidade dele (ou de substâncias químicas) praticamente de forma ilimitada. E isso se logra mediante os passos de isolar ou separar um fragmento do ADN, inserir esse fragmento em um vetor recombinante, introduzir o vetor recombinante em um micro-organismo ou uma célula "anfitriã" para obter uma célula recombinada, selecionar as células recombinadas e provocar sua atividade em condições favoráveis à expressão do gene, e assim obter o produto desejado. E desse se obtém, por exemplo, a insulina e o interferon.

A técnica de fusão celular consiste em fundir dois tipos de células que têm uma característica particular e em selecionar as células que têm características dos dois tipos e células usadas. Essa técnica é a utilizada para melhorar plantas e para produzir hibridomas, produtores de anticorpos monoclonais.

\subsubsection{Aplicações}

Essa nova tecnologia proporciona uma melhoria no bem-estar geral e o aumento de vantagens competitivas, especialmente nos setores farmacêuticos e químicos, de modo a gerar consequências, por exemplo, na agricultura e alimentação, além de proporcionar efeitos junto ao meio ambiente. Pode-se afirmar também que a integração da Biotecnologia com 
essa ampla gama de setores não foi uniforme, mas se pode dizer, sem margem de erro, que o setor farmacêutico é a parte considerável na qual a tecnologia biológica continua a predominar.

Em uma grande diversidade de planos e orientações, convém se dizer que a Biotecnologia moderna desenvolveu e enriqueceu os distintos papeis do processo dos fatores de produção. E em nossa época, - e porque não dizer também de forma promissora que no futuro -, poderá ser ela a tecnologia central, capaz de poder cumprir uma função-chave ou ser uma tecnologia de suporte, ao afiançar novas formas de vida.

Sem dúvida, uma proximidade ontológica do desenvolvimento e da aplicação de uma nova tecnologia é a existência de transformações sociais, econômicas e até ambientais. E essas importantes e peculiares consequências, entretanto, avançam, e passam a oferecer muito mais condições para o surgimento de novos tipos de relações entre os agentes econômicos e formas de alteração e aperfeiçoamento das forças produtivas e, não se poderia deixar de lembrar, uma situação inegável de vantagem, que é a melhoria do desempenho na capacidade competitiva no mercado relevante. É igualmente necessário fazer constar que essas consequências exercem no plano social, especialmente nas condições de vida e saúde humanas, verdadeiras mutações, pois tendem a melhorar as conquistas e o desenvolvimento da população, em uma harmonia uniforme, e em amplo dinamismo, com resultados econômicos e sociais gerais.

Ao analisarmos o modo de vida do povo em tempos atuais, um conjunto determinado de métodos, tipos e formas de atividade contribuem para um concreto bem estar geral, tal como a descoberta de novas vacinas para enfermidades humanas e a engenharia genética para reduzir a transmissão de enfermidades animais. E com a mesma síntese que tratamos as questões anteriores, deve ser lembrado que as essências dessas novas ideias oferecem, em termos ambientais, os instrumentos destinados ao desenvolvimento das atividades amplamente consideradas de uma forma sustentável, como a proteção dos recursos naturais e da biodiversidade. Por meio das denominadas estratégias de bioprevenção ou biorremediação, a 
sustentabilidade encontrará vastos círculos de uma influência que ultrapassa a todas as outras formas de permanência e preservação.

O postulado central é que a Biotecnologia proporciona uma alteração no estado das coisas e mudanças substanciais nos efeitos incrementais, e ao seu próprio tempo e em adequadas condições o que seriam verdadeiras atitudes disruptivas, ou mesmo inclusões radicais, não obstante se ter a sabença de que esses últimos são raros e infrequentes, embora imprevisíveis. E nesse sentido, cabe assinalar que cada um desses efeitos implica um desafio capaz de fundamentar uma variedade de políticas públicas a médio e longo prazo.

\subsection{Panorama mundial e regional}

\subsubsection{Histórico}

A Biotecnologia moderna, ou seja, o pensamento da tecnologia biológica do período mais recente da ciência, é originária dos Estados Unidos da América. Esse país (EUA) foi o pioneiro no desenvolvimento da Biotecnologia e é, ainda hoje, o líder inconteste nesse campo. E são igualmente suas as primeiras empresas a se formarem nesse setor, no período compreendido entre os fins dos anos 70 e princípios dos anos 80 . Fora do espaço norte-americano, pode-se mencionar as empresas europeias, constituídas na década de 90, com a característica de serem pequenas ou medianas, se comparadas com as homólogas dos Estados Unidos.

Não será difícil exagerar a influência da pesquisa norte-americana em nível mundial, pois os Estados Unidos da América ainda dominam esse conhecimento em todos os seus segmentos mais conhecidos: genética vegetal e animal, alimentos e medicamentos. Essas três áreas se concentram em um complexo interinstitucional estabelecido em um tripé: 
laboratórios públicos, universidades e empresas de biotecnologia. A Europa reproduz esse modelo e, com menos ênfases nos laboratórios públicos, o Japão e a China. Os Estados Unidos da América, a Europa e o Japão fizeram gastos públicos especialmente dirigidos ao setor de saúde (gasto público em biotecnologia em pesquisa e desenvolvimento no ano de 2005: nos EUA 23 bilhões de dólares; países europeus membros da OCDE (Organização para a Cooperação e Desenvolvimento Econômico) 4 bilhões de dólares e outros países membros da OCDE um bilhão e meio de dólares.

E já é previsto que para o ano de 2030 as aplicações do setor analisado poderiam representar cerca de $3 \%$ do Produto Interno Bruto (PIB) dos países da OCDE. Em valores absolutos esse percentual será maior que os PIBs dos países em desenvolvimento. E esses dados não incluem o impacto futuro do uso de biocombustíveis nas economias desenvolvidas.

Tão profunda é a transformação da Biotecnologia do mundo moderno que nem mesmo as crises econômicas têm gerado grandes diminuições na sua pesquisa e desenvolvimento. Essas mudanças de situação econômica têm estimulado a racionalização dos custos e a concentrar cada vez mais a atividade. É sumamente difícil traçar um quadro completo, mas, deve ser destacado que, para as pequenas e médias empresas, o resultado prático foi um aumento da capacidade de pesquisa e desenvolvimento e de um incremento na sua produtividade.

As economias periféricas e regionais, que tardiamente despertaram para o impacto da tecnologia biológica, encontraram e estabeleceram seu espaço mediante uma aceleração em importantes aspectos da indústria biotecnológica, tais como a indústria farmacêutica, química, alimentar e do setor agrícola. Essas atividades se desenvolveram por transferência de tecnologia, mas, hoje, algumas delas já mantêm o desenvolvimento de atividade de ponta em alguns setores, como seriam exemplo, em uma ou outra área, a Índia e o Brasil, se não considerarmos mais o Extremo Oriente e Israel como economias periféricas. As instituições e empresas brasileiras de biotecnologia são direta ou indiretamente beneficiadas pelo esforço superavitário do Brasil no agronegócio. Parece forçoso dizer que, a 
despeito do volume de negócios agrícolas do Brasil, as empresas da área biotecnológica são ainda pequenas, se comparadas com as estrangeiras, mas já possuem certa excelência técnica e estão estreitamente vinculadas aos sistemas de ciência e tecnologia. A pesquisa no Brasil relacionada com a área da saúde teve um notável impulso pela iniciativa das universidades públicas, institutos de pesquisa e empresas governamentais, das quais se poderia destacar a Empresa Brasileira de Pesquisa Agropecuária Embrapa.

A biologia molecular e sua aplicação à produção de meios de diagnósticos, vacinas e agentes terapêuticos mereceram muita atenção, especialmente para as doenças tropicais, mas, inegavelmente, a agropecuária foi a mais vitoriosa em resultados comparativos. É de se reconhecer que o governo brasileiro enveredou esforços para a promoção biotecnológica, não somente para atender aos reclamos da saúde pública, mas, também, com o objetivo final de estimular o desenvolvimento industrial. Não é possível indicar as características do setor privado brasileiro, diante do seu dinamismo e concentração empresarial, mas um distintivo especial haveria de ser ressaltado: a criação de polos, parques como centros biotecnológicos em todas as cinco regiões geográficas do País.

\subsubsection{A tecnologia biológica e sua importância no mundo atual}

Se prescindirmos do natural aperfeiçoamento, evolução e progresso da humanidade, em suas conquistas sociais e econômicas, os conhecimentos científicos e tecnológicos constituem elementos essenciais do reflexo da evolução real do mundo. Demais disso, servem para lograr uma posição de vantagem em todo o conteúdo concreto dos aspectos da trajetória histórica do desenvolvimento humano. É completamente compreensível pensar em uma área na qual não esteja presente alguma forma manifesta 
de tecnologia, e isso ocorre desde operações simples e quotidianas como o pagamento de um serviço de transporte público, até a geração de energia nuclear ou a exploração espacial. É de se entender que, todo esse conjunto de conhecimentos tecnológicos representa um altíssimo valor, não somente estratégico e político, senão também econômico, portanto, suscetível de ser objeto de negócios mercantis, que graças às suas potenciais repercussões na sociedade, será, em maior ou menor medida, a forma de transição dos limites da ciência de bem do mais puro ponto de vista abstrato para o ponto de vista concreto.

É evidente que a realidade não se limita somente a esse tipo de contradição (abstrato e concreto), especialmente em um assunto tão amplo como a Biotecnologia. Mas é necessário lembrar que contradições internas presidem o objeto de uma pesquisa e o processo de seu conhecimento.

Se a pesquisa houvesse de se aprofundar por uma das vias das ciências em geral, haveríamos de bifurcar outros aspectos contraditórios e úteis para o estudo do fornecimento de tecnologia, além dos pontos de vista abstrato e teórico acima mencionados, tais como aqueles que seriam simples e complexos, o geral e o particular, ou o estático e o dinâmico, se considerássemos apenas alguns aspectos da conexão das ciências.

\subsubsection{Da Biotecnologia no mundo}

A Biotecnologia pode ser entendida como uma engenharia genética e, particularmente, como uma manipulação do ADN recombinado. Mesmo em diferentes áreas, seja nas tradicionais como a tecnologia farmacêutica, que mantém organismos vivos involucrados e que normalmente podem se reproduzir, o que mais causa certa perturbação muito cedo na evolução das leis e do fato de que muitos dos produtos e processos que são patenteáveis sejam derivados de produtos e processos naturais. 
Assinalamos mais uma vez que a Biotecnologia se refere às tecnologias que utilizam organismos vivos. E a palavratécnica faz referência basicamente à genética, à microbiologia, à biologia e à bioquímica e seus campos de aplicação, que se encontram relacionados com a agricultura, a química, a indústria farmacêutica, a saúde, a produção de alimentos e a conservação do meio ambiente.

Os organismos vivos utilizados na Biotecnologia são os organismos vivos em seu estado natural (como os organismos usados em processos de fermentação), os organismos obtidos por meios convencionais (o procedimento essencialmente biológico) de seleção, cruzamento ou mutação, e os organismos modificados por novas técnicas, como a engenharia genérica ou a técnica da fusão celular.

\subsubsection{A concentração do conhecimento biotecnológico}

Os cientistas e pesquisadores parecem enxergar com lucidez o caráter peculiar da Biotecnologia, e sua diferença fundamental no quadro do conhecimento geral. Essa percepção científica, intensamente sentida e expressa com vigor, permitiu, especialmente a um grupo de países, enfrentar com êxito o desafio do bem-estar dos povos e das necessidades dominantes de nossa civilização. É nesse ponto que se faz um questionamento sobre as carências materiais do indivíduo e de sua capacidade de proporcionar resultados práticos e úteis para supri-las. Sem entrar em minúcias, a concentração da produção e do conhecimento biotecnológico representam uma das características mais discrepantes ou contraditórias do progresso e das melhorias de condições da vida moderna. E é embasado nessa premissa de êxito contraditório, que se extraem dos fatos objetivos o quanto são polarizados os esforços e os gastos com a pesquisa e desenvolvimento e, por sua vez, o quanto é considerável a falta de homogeneidade entre os países produtores e consumidores de tecnologia. A experiência nos ensina que tudo muda, e que nada há de 
estável no domínio do conhecimento científico e tecnológico. Entretanto, seja por diferenças de desenvolvimento prévio ao próprio conhecimento em curso, seja pela falta de capacidade de financiamento da pesquisa ou de manter um elenco de pesquisadores, essa divisão multicolorida do uso da tecnologia é reduzida a poucos matizes quanto se trata de conhecer quem produz o conhecimento. Do ponto de vista dos benefícios, a tecnologia atinge a todos, mas não é estruturada e paritária quanto ao reduzido grupo de países que venceram os desafios dos resultados práticos de dominar os instrumentos tecnológicos. Sob a influência dessa premissa de contradição, registramos que $15 \%$ apenas da produção mundial proveem a maior parte das inovações tecnológicas no mundo, ao passo que menos da metade da população mundial é capaz de adaptar essas tecnologias na produção e consumo. E mesmo se pode dizer, de verdade, que todo o restante da população, ou seja, um terço da população mundial, se encontra tecnologicamente isolada, sem condições técnicas sequer de adaptar tecnologias estrangeiras ou mesmo de iniciar pesquisa e desenvolvimento próprios.

Em um breve resumo, que bem poderia ostentar a qualidade de uma panorâmica da produção da tecnologia biológica, a formação das ideias fundamentais da Biotecnologia não serviu para o progresso científico somente, mas, também, para forjar uma situação única e privilegiada. E se tornou um verdadeiro paradoxo na aparição dos princípios e ideais fundamentais da explicação científica, incompatível com a tradição de acelerar o progresso mediante a promoção e divulgação dos avanços tecnológicos. A finalidade da criação científica se modifica para se tornar um interesse de conceito econômico em seu movimento de aceleração do progresso científico, e a gerar um conhecimento mais concentrado. Sintetizado esse efeito econômico, o rumo das transformações dos instrumentos das ciências e dos experimentos realizados incluiria não somente a elevação do bemestar geral, mas a concentração econômica da tecnologia. A par dos traços fundamentais comuns da concentração de produção e de desenvolvimento tecnológico, a produção do conhecimento 
biotecnológico ocupa uma posição peculiar porque conta com menos representantes que o rol dos países produtores de tecnologia em geral.

Enfim, se na produção tecnológica geral é uma pequena parte do mundo que produz conhecimento, o conhecimento da Biotecnologia é limitado a uns poucos países. Há razões para se pensar em uma solução para esses problemas, mas há igualmente motivos para se reconhecer a atitude desinteressada das instituições na pesquisa biotecnológica. $\mathrm{O}$ que significaria sublinhar a falta de quadros ou de recursos para investimentos em pesquisa e desenvolvimento, mas, pode-se igualmente atribuir também essa situação ao descaso ou ao desdém com que os propósitos do desenvolvimento nacional sejam estabelecidos por cada sociedade. A aceitação dessas afirmações implica ter de se enfrentar problemas aparentemente insolúveis. Por outro lado, como chegar a outros resultados se a UNCTAD (United Nations Conference on Trade and Development [Conferência das Nações Unidas sobre Comércio e Desenvolvimento]) em estudo conhecimento constatou que, só nove países da OCDE concentram $90 \%$ dos gastos mundiais de novas tecnologias, enquanto que o percentual de gasto dos países em vias de desenvolvimento em matéria de pesquisa e desenvolvimento representa somente $6 \%$ dos gastos mundiais?

\subsubsection{O elevado custo da produção biotecnológica}

A produção tecnológica está associada a processos de inovação, pesquisa e desenvolvimento, os quais implicam um alto custo econômico que, em sua maioria de casos, só pode ser assumido por aqueles que dispõem de recursos suficientes para fazer frente a essas exigências. Lamentavelmente, a propriedade industrial - disciplina encarregada da proteção de novos desenvolvimentos-, não só não tem dado solução a essa problemática, senão de alguma forma que a provocar uma verdadeira piora ou prejuízo. O exemplo paradigmático dessa situação se encontra no sistema de patentes de invenção, que dentro dessa disciplina, representa a 
forma mais usual de proteger os conhecimentos tecnológicos. Devido ao princípio da territorialidade que rege a proteção da propriedade industrial, o titular de uma nova tecnologia suscetível de ser protegida, por meio do sistema de patentes, deverá dirigir-se a quantos territórios queira explorar de forma exclusiva sua invenção e em cada um deles deverá dirigir-se a quantos territórios queira explorar de forma exclusiva sua invenção e em cada um deles levar a cabo o procedimento administrativo para lograr a concessão da patente. Para tal fim, será necessário o pagamento de taxas oficiais que cada país estabeleça, mais os honorários profissionais de um agente local, que o represente no processo de registro.

Essas peculiaridades que se examinam em conjunto, somadas aos altos custos da pesquisa e desenvolvimento, associados à proteção dos resultados dessas atividades conduzem a que, na maioria dos casos, os titulares de direitos de propriedade intelectual sobre os conhecimentos biotecnológicos sejam empresas com um importante poder econômico, bem seja porque desenvolveram sua própria tecnologia ou porque adquiriram os direitos contratualmente.

Adicionalmente ao já exposto, outro efeito que gera o elevado estado de custo da produção e proteção dos conhecimentos tecnológicos radica em que a contribuição desses ao esquema produtivo do país receptor é mínima, devido, em muitas ocasiões, ao que os processos de adaptação das condições locais supõem um esforço econômico adicional da aquisição dos conhecimentos tecnológicos. Essa informação foi coletada em um documento da UNCTAD, apresentado no desenvolvimento das negociações sobre o Código Internacional de Conduta sobre Transferência de tecnologia no que se expõe:

"A dependência dos países em vias de desenvolvimento é consideravelmente maior e a contribuição da tecnologia adquirida é mais baixa que para outros países importadores finais de tecnologia porque os países em vias de desenvolvimento não têm, na maior parte dos casos, a capacidade de organização, investigação e de engenharia para poder 
ajustar, adaptar e assimilar a tecnologia importada aos seus próprios necessitados."

\section{PARTE 2 - A TRANSFERÊNCIA DE TECNOLOGIA}

\subsection{Noção}

Por transferência de tecnologia se entende um complexo deslocamento de situações, na qual o objeto material é o conhecimento tecnológico. Os juristas parecem tomar a ideia de transferência como abrangida na temática contratual. Dessa forma, costumam empregar a figura da transferência de tecnologia como associada, ou mesmo uma classe de contrato, ao contrato de transferência de tecnologia. Alguns autores vão além da função técnica do contrato e usam o contrato de licença em sentido amplo, para se referirem à concessão feita por um titular de patente, modelo de utilidade, assistência técnica ou mesmo segredo industrial. Há ainda quem prefira um significado mais restrito e usam a figura como contrato delicença. A falta de harmonização não impede que se reconheça que esses contratos são todos mistos ou coligados (pois o coligado não forma uma nova espécie contratual, como ocorre com o misto), com variações em número não conhecido.

Nesses contratos, se outorga a um cessionário os conhecimentos necessários para compor a tecnologia a ser utilizada. Normalmente vão acompanhados de uma série de disposições sobre se revelam as condições exigidas pelo cedente, dentre as quais a qualidade e uso de marca. E igualmente ordinária é a remuneração mais conhecida na sua versão anglosaxônica "royalties". Royalties corresponderia, segundo a literatura especializada, ao termo realdades, em português, que é usado neste texto. 


\subsection{Cláusulas mais comuns nos contratos de transferência de tecnologia}

A natureza mista ou coligada dos contratos de transferência de tecnologia não impede a formação de um núcleo comum de disposições, que resultam da sua própria finalidade, a despeito das partes se convencerem de que outras cláusulas poderão ser apostas ao negócio.

Dentre as cláusulas conhecidas é de se citar as seguintes:

(1) Determinação dos deveres do cedente;

(2) Os deveres do cessionário;

(3) Caráter temporal da tecnologia: definitiva ou temporária;

(4) Forma de pagamento;

(5) Unidade monetária;

(6) Bases do cálculo das realdades (royalties);

(7) Efeitos dos tributos na transferência;

(8) Duração do contrato;

(9) Indicação da produção mínima (ou máxima) dos produtos gerados pela tecnologia;

(10) Limitações e condições para o uso da tecnologia;

(11) Mercado dentro do qual poderá atuar do cessionário;

(12) Assistência técnica que prestará ao cedente;

(13) Dever de preservar o segredo sobre a tecnologia;

(14) Exigências quanto ao modo de empregar a tecnologia;

(15) Qualidade dos materiais a serem usados;

(16) Qualidade dos bens produzidos;

(17) Garantias e sanções por descumprimento contratual; 
(18) Causas de extinção do contrato;

(19) Retrocessão de toda tecnologia desenvolvida;

(20) Designação do foro competente para dirimir o conflito;

(21) Previsão de arbitragem.

\subsection{As obrigações de meio e resultado}

O curso do desenvolvimento das Ciências Jurídicas, como de toda ciência em geral, se revela em distintas maneiras, em igualmente distintas etapas históricas. E uma tendência está dirigida à transferência de tecnologia, na forma de se utilizar as obrigações contratuais: as obrigações de meio e de resultado.

Para elaborar um sistema de comunicações entre credores e devedores, baseia-se o Direito em formas relativas e marcadas por um conteúdo econômico. Assim se explica de modo direto e objetivo a obrigação. Surge, então, imediatamente, esta pergunta: qual a relação da obrigação com os contratos de transferência de tecnologia?

Muitas seriam as formas de se responder. Haveria de se perguntar, então, se um contrato não seria fonte de direitos e deveres para as partes cocontratantes? E a afirmação da resposta se explica, segundo muitas opiniões, de que esses direitos e deveres relacionados às partes são justamente as obrigações.

Coube ao jurista francês Demogue a construção teórica da ideia de obrigação mais peculiar ao contrato de transferência de tecnologia: a obrigação de meio e de resultado. Sua forma autoenunciativa de classificação destaca que na obrigação de resultado, a execução é atingida quando o devedor cumpre o objetivo final; ao passo que na de meio, o desvio de certa conduta ou omissão em certas precauções a que se comprometeu o devedor para não atingir o resultado esperado. 
Por conseguinte, em uma transferência de tecnologia, o contrato traz consigo correspondente propósito de ceder com êxito o produto da negociação: a tecnologia. E em favor desse esquema há o pensamento comum de que se a tecnologia não foi transferida, o contrato terá se frustrado na sua finalidade. Muitos trabalhos relacionados aos contratos de transferência de tecnologia assentam-se nessa verdadeira condição em movimento para alcançar o resultado final do negócio.

Em concordância com as condições acima expostas, a transferência de biotecnologia deveria ser, igualmente, uma utilização de correspondência biunívoca das consequências obrigacionais dessa construção teórica tal como usada no mundo comercial, como é o contrato de transferência de tecnologia.

Como se vê, há uma certa semelhança entre os efeitos do contrato de transferência de tecnologia e o contrato de transferência de biotecnologia, uma vez que tanto um quanto o outro procuram a mesma coisa, ou seja, um resultado. E uma união de ideias de um contrato e outro conduziria a uma formação comum e ao aproveitamento direto de toda experiência já conhecida e usada nos contratos de transferência de tecnologia em geral.

A diferença consiste só em que a cadeia biológica, na qual se assenta a Biotecnologia, pode não se realizar. A formação combinada dos elementos decisivos para o resultado pode não ocorrer. E isso se faz evidente pelas diferentes condições de clima e temperatura, dentre outros, na geração de resultados concretos, esperados pela aplicação de um contrato com obrigações, marcadamente de resultado, como ocorre no comum dos casos com a transferência de tecnologia.

Se é conhecido o pluralismo da vida, e sabemos que o meio ambiente é tão complexo quanto as demais complexidades conhecidas, parece ser um erro resolver o problema da transferência de biotecnologia sem ignorar a antítese mecânico e orgânico e de algo que está vivo e algo que não tem vida. 
Uma vida se vê frente a si mesma e mais nada além da morte. Se não há vida, há impotência e inanidade. É nessa cômoda antítese do orgânico e do mecânico, que todo desdobramento deve transcorrer. O ponto de vista mecânico da transferência de tecnologia não leva a uma adesão ao uso da obrigação de resultado nas condições qualitativas gerais para as condições quantitativas de probabilidades de uma transferência de biotecnologia. Seria exemplo a arrumação da estrutura de certo tipo de micro-organismo para ser utilizado em condições climáticas distintas de sua formação original. E esse resultado estará a depender mais das condições exigidas para uma apreciação de obrigações de meio do que de resultado. É que, sem o esforço esperado, o resultado pode não ocorrer, diferentemente de ser o resultado mesmo o esforço para alcançá-lo ter sido o mais corriqueiro e mediano, dentro das condições do contrato. É dessa forma que uma fábrica pode ser montada já com elementos pré-fabricados e alcançar o resultado com o funcionamento das máquinas a contento.

\section{PARTE 3 A TRANSMISSÃO DO CONHECIMENTO BIOTECNOLÓGICO}

\subsection{A importância da transferência de tecnologia para a difusão do conhecimento}

A promoção tecnológica e o seu consequente desenvolvimento são as reais prioridades em uma cessão de tecnologia. $\mathrm{E}$ a forma mais abreviada de não se retornar aos primórdios para alcançar os resultados no estado da arte é a via do fornecimento de tecnologia já produzida. Do contrário, toda a pesquisa e desenvolvimento teria que repetir os movimentos mais elementares em sucessão para alcançar conhecimentos exigidos em mercados competitivos, como o consumidor em tempos atuais. Essa política de uma construção original do conhecimento exigiria grandes e 
contínuos investimentos, que muito bem podem ser resolvidos com uma equivalência de conhecimento tecnológico, alcançável por meio de uma transferência.

Demais disso, as companhias que competem em um dado mercado relevante esperam beneficiar-se do menor custo, se comparado com os gastos com pesquisa e desenvolvimento para novos produtos. Os riscos dos negócios não são normalmente acompanhados por iniciativas de produção original do conhecimento, mas, sim, da busca incessante de lucros em seus empreendimentos. Esse resultado que ajuste os custos com os benefícios são, regularmente, resolvidos com a aquisição de tecnologia de outrem, mediante uma transferência negociada.

\subsection{A função social dos processos de transferência de biotecnologia}

A transferência de tecnologia implementada por meio do contrato de transferência de licença pode ter um significado mais além do que o meramente econômico, alcançando a possibilidade de cumprir uma função social. Essa visão foi contemplada em diferentes textos normativos e iniciativas de harmonização. Um claro exemplo dessa visão social se pode encontrar nos artigos $7^{\circ}$ e 66.a do Acordo sobre os aspectos dos direitos de propriedade intelectual relacionados ao comércio (ADPIC), mais conhecido pelo acrônimo em inglês TRIPS.

O mesmo está coletado em um informe do grupo de trabalho sobre comércio e transferência de tecnologia ao Conselho Geral da Organização Mundial de Comércio (OMC), onde se põe em manifesto a projeção social dos processos de transferência de tecnologia, ao sustentar que esses constituem um dos mecanismos por excelência para procurar o melhoramento das condições de vida dos países em desenvolvimento. 
Os argumentos assinalados anteriormente servem para ilustrar a função social que têm os processos de transferência de tecnológica que, tal como sustentam pronunciamentos de diferentes instituições internacionais, se convertem em uma poderosa ferramenta para alcançar o objetivo de melhorar as condições econômicas e sociais dos países com um grau menor de desenvolvimento econômico e tecnológico.

\subsection{O contrato como meio de difusão da transferência de tecnologia}

A base histórico-cognoscitiva dos contratos modernos remonta ao período da civilização romana, que não somente estruturou a figura do contrato, como o definiu com a principal característica a ser utilizada neste texto: a de ser um acordo de vontades a respeito de um mesmo ponto. E a importância de se lembrar dessa máxima valoração da vontade está em que, uma vez celebrado o contrato, com a observância das formalidades de estilo, estará o contrato apto a gerar obrigações - fator da mais lídima essencialidade, sem o qual não haveria direitos e deveres das partes.

Não obstante o rigorismo formal para as formas contratuais, com o passar do tempo e o desenvolvimento das atividades em geral, a função do contrato se alterou, e, sem perder a sua pureza e estrutura, serviu para conformar os interesses na complexidade da vida em nossos tempos, sem que sua força vinculante fosse alterada.

Sem o contrato, o homo economicus estancaria suas atividades, porque é o contrato que proporciona a subsistência da toda a gente, sem o qual a vida individual regrediria, e a atividade do homem limitar-se-ia aos momentos primários do percurso humano.

Outra virtude se há de considerar. Ao lado da função econômica, serve o contrato como forma civilizadora e desenvolvimentista. É o contrato que promove a circulação de riqueza, aproxima os homens e reduz as diferenças, ao munir todos de instrumentos jurídicos para alcançar os fins 
determinados pelos interesses econômicos, e porque não dizer, também os interesses da sociedade como um todo. Só resta lembrar que é por dele que a tecnologia se desenvolve e se propaga.

É através das formas e obrigações contratuais que se difundem os avanços da tecnologia. E tudo isso se reflete na ideia de que, um acordo de vontades pode obrigar uma pessoa a ceder a outra, para que os aproveitem, os conhecimentos que têm de processo especial de fabricação, informações ou práticas originais ou só por essa pessoa conhecidos.

Para a análise, esclarecimento e solução da transmissão do conhecimento, deve ser assinalado que ele se dá mediante simples entrega de planos, desenhos ou outros papéis, por meio do fornecimento do material, que incorpore os conhecimentos ou, finalmente, pelo ensino prático de sua aplicação, seja por meio de técnicos enviados para esse fim, seja pela admissão, na sua própria fábrica, de pessoas designadas para aprender, praticando o processo de fabricação.

\subsection{Dificuldades encontradas na propriedade intelectual para os processos de transferência de tecnologia}

O desdobramento de todo o campo do conhecimento e da atividade do homem encontrou também seus reflexos na elaboração dos princípios jurídicos que norteiam a construção de um sistema de tutela dos direitos, que resultariam do desenvolvimento e do aperfeiçoamento dos bens decorrentes de todo o esforço e trabalho.

A disciplina da propriedade intelectual adota uma pluralidade de técnicas e instrumentos de proteção dos interesses dos seus titulares. Não há dúvida alguma que não existe apenas uma, mas muitas formas de tutela da propriedade intelectual. E em todas elas se fala de uma tipicidade e um numerus clausus de direitos exclusivos. 
Por conseguinte, surge a eleição de um dos principais elementos norteadores da propriedade intelectual, ao estabelecer a relação entre as formas da propriedade intelectual e a sua tutela jurídica correspondente proposição firmada por Tullio Ascarelli que constitui a chave da classificação da Biotecnologia.

Se se admite a premissa de que há uma tutela jurídica para cada forma de manifestação da propriedade intelectual, os distintos aspectos da Biotecnologia seriam capazes de merecer uma única e exclusiva proteção? Essa indagação vai conduzir as linhas mestras desta pesquisa.

Conquanto seja a disciplina da propriedade intelectual o meio mais idôneo para a proteção da tecnologia, uma vez que ela é identificada com os direitos dos produtores do conhecimento tecnológico, seus defensores são tomados em consideração somente porque concordam com as teses dominantes dos países produtores, de quem sofrem influência quase decisiva. E como é fortemente centralizado, não tolera senão uma orientação de acirramento dessa concentração, ficando a reclamar a consolidação e sistematização mais eficazes por parte de todos os produtores e remetendo apenas ao plano da absorção ou comportamento passivo um verdadeiro estigma para os países remanescentes.

O principal efeito dessa proteção, e que exerceu e continua exercendo a influência mais profunda e duradoura, é o limite especial dos direitos de propriedade industrial da maneira tal como é estabelecido, qual seja, mediante outorga do Estado. Uma experiência original e sem paralelo é o acesso geral da população aos benefícios associados ao desenvolvimento farmacêutico que atribuiu aos seus criadores um poder lastreado em um instinto de dominação que beira aos limites da soberania dos Estados, quando muito não a arrefece ou fragiliza.

Uma sucessão de acontecimentos conduz ao problema da concentração do conhecimento e ocupa o centro das questões do sistema da transferência de tecnologia. E é também o principal obstáculo a ser superado. Ele exerce uma função demolidora na multiplicação do conhecimento a ser difundido, 
o caráter territorial dos direitos do exclusivo constitui a segunda maior dificuldade. A territorialidade e o princípio que a acompanha - o princípio da territorialidade -, afetam a maioria dos direitos de propriedade intelectual, e de forma mais exclusiva, a transferência de tecnologia. Para bem compreender essa ideia de limite territorial, é necessário lembrar que, a possibilidade de ser explorado simultaneamente em distintas partes do mundo, significa que os altos custos assinalados lhe servem de base. E é nessa realidade, nem ideal nem essencial, que os recursos econômicos adequados para fazer frente a esses custos poderiam gozar da proteção outorgada pelo Estado.

Nesse assunto, pode-se apreciar claramente a dificuldade para encontrar um equilíbrio entre os interesses farmacêuticos, que argumentam sobre a necessidade de obter os direitos exclusivos do que é desenvolvido, com o fim de seguir adiante com seus processos de pesquisa, e os interesses da sociedade no geral, que necessitam ter a seu alcance os tratamentos médicos para enfrentar enfermidades como o câncer e a SIDA (Síndrome da Imunodeficiência Adquirida, mais conhecida como AIDS) a preços razoáveis.

\subsection{Desequilíbrio no poder de negociação das partes em um contrato de transferência de tecnologia}

A forma mesma que por séculos tem valorado e protegido os produtos do intelecto, e serviu para todos aqueles que criaram ou desenvolveram conhecimentos úteis em seus diversos tipos de proteção em todo o mundo, criou entraves que, de maneira combinada com as leis de comércio internacional, geram verdadeiras escalas em linha vertical até o desenvolvimento econômico.

E o estado do comércio e da economia mundial circunscreve os produtos intelectuais nas suas categorias básicas: direitos autorais, patentes, marcas, segredos de negócios, além das novas categorias, que 
muito bem podem ser representadas pelo circuitointegrado, mais conhecido pela sua versão anglófona chip, em referência à pastilha sólida que se constitui e aparenta.

Esse esquema geral tem logrado êxito para os fins a que se destina, mas não é capaz de adaptar as novas formas conhecidas de criatividade e inovação para os demais países, não produtores de tecnologia. É suficientemente engenhoso na sua capacidade de proteção e tutela, mas, proporcionalmente, se move em escala mundial, para transformar os demais países não-produtores de tecnologia em meros consumidores e protetores de direitos que, em realidade, não conhecem em sua essência ou concepção.

A tecnologia não flui em seu conhecimento, mas em seu uso. E os efeitos que desenvolve, embora tenha um papel facilitador do uso da tecnologia nova e útil, não estimula o crescimento comercial bilateral, nem aproveita o ritmo do desenvolvimento econômico em ampla medida.

Ao adotar esse sistema de importação de tecnologia, todo um país se submete a uma custosa dependência econômica pretensamente perpétua, e impõe uma verdadeira desvantagem, de modo a formar um desequilíbrio das partes em negócios que venham a ter algum papel positivo nos negócios de transferência de biotecnologia, e da tecnologia em geral.

\subsection{As vias para se levar a cabo uma transferência biotecnológica}

Para resolver essa situação, devem ser incentivadas as políticas cientificas governamentais e universitárias destinadas a projetos biotecnológicos em pesquisa e desenvolvimento. E essa última redundará em um aumento substancial da quantidade de publicações científicas e aumento equivalente no número de patentes. Paralelamente à transferência de tecnologia, devemos considerar, nesta pesquisa, que a reestruturação 
das políticas governamentais para a Biotecnologia deve seguir os seguintes passos: (1) publicações cientificas de acesso aberto, (2) de livros científicos, (3) de patentes; (4) de produtos relacionados aos existentes no mercado.

A escolha da atividade inventiva tem que ser suscetível de aplicação industrial, cumprindo com os três requisitos legais básicos para o patenteamento. O melhor exemplo para ilustrar a pesquisa é o caso mais relacionado como tema central de investigação, que é o caso Chakrabarty.

Sem que se trate de uma tese alentada e grandiosa para descrever e classificar a transferência biotecnológica, toda compreensão do uso do método conceitual tem, além de um amplo espaço de argumentação, a possibilidade de ser demonstrado. Tratando-se de pôr como base em todo raciocínio jurídico sobre a forma como o jurista descreveria uma transferência de biotecnologia, os primeiros conceitos extraídos foram exatamente os abstratos. Faz-se necessária a lembrança desenvolvida precisamente na concepção teórica, no primeiro digno de repercussão acerca do conhecimento biotecnológico: o caso Chakrabarty.

Não é possível que sejam indicadas, naturalmente, as características gerais que acompanharam o debate e o desenvolvimento do caso Chakrabarty. Interpretando os fenômenos desenvolvidos, pode-se qualificar alguns dos aspectos particulares do ocorrido. No dia 17 de março de 1980, a Suprema Corte dos Estados Unidos da América votou, por maioria, a possibilidade de concessão do direito de registro de patente para uma linhagem de bactéria. A espécie era do gênero Pseudomonas, transportadora de segmentos de $\mathrm{ADN}$ (ácido desoxirribonucleico) estranhos, denominados plasmídios, capazes de conferir características genéticas distintas do que era encontrado, naturalmente, na bactéria.

Esse pesquisador, Ananda Chakrabarty, afirmava que teria "inventado" um micro-organismo que não ocorria na natureza e que exibia importantes propriedades para emprego geral, especialmente pelo derramamento indevido de petróleo, já que teria a capacidade de consumir óleo derramado. 
Essa controvérsia foi o marco inicial dos estudos jurídicos sobre a importância do sistema de patentes de seres vivos e de sua contribuição para a tecnologia biológica, ou mais especificamente, para a Biotecnologia. Sua contribuição, entretanto, vai muito além da própria sistemática das patentes, porque ocupará o lugar central nos problemas futuros de transferência de Biotecnologia.

\section{CONCLUSÕES}

Da experiência de uma análise pretensamente segura manifesta-se a tendência principal, proclamada e divulgada pelas universidades mais modernas, sejam nacionais sejam estrangeiras, de primar pelo desenvolvimento sócio-político dos povos, pelo engrandecimento e dignidade da pessoa humana, nas suas mais variadas acepções, como, por exemplo, na pesquisa realizada, resultante dos problemas mais enraizados e verdadeiramente fundamentais entre tecnologia e desenvolvimento biológico. O processo nacional de evolução tecnológica, tratado nesta pesquisa em particular, atravessou determinadas etapas que, a despeito de serem rápidas ou mais lentas, conforme as condições de dificuldade, em tempo algum ignorou o nível de atividade de alta relevância dos temas relacionados à promoção tecnológica, à capacidade das instituições nacionais e, como não poderia deixar de ser, o esforço contrário ao desenvolvimento do País.

A contraposição entre as forças antidesenvolvimentistas representadas pela reação à pesquisa e ao deliberado não-investimento, somado ao déficit de quadros - e aquelas que primam pelo desenvolvimento do Brasil - não foram ignoradas, mas, ao contrário, tratadas como algo que deve ser impreterivelmente considerado e avaliado como uma das manifestações da tensão entre duas verdadeiras linhas de atuação na política econômica mundial. Os mais resistentes meios de elevação ao progresso e ao desenvolvimento do País, ou mesmo de outros 
países, foram considerados na pesquisa, especialmente pela orientação agressiva de grandes grupos econômicos, na tentativa de impedir o processo de liberação tecnológica em escala mundial. Os países em desenvolvimento - algo que não se deve olvidar-, são os maiores destinatários das ações desses grupos etnocêntricos organizados em forma de companhias multinacionais, que, quando muito, reforçam a riqueza concentrada nos seus países de origem e, onde, normalmente, têm a sua sede.

Do que vem a ser ressaltado, se evidencia que o estágio foi norteado pelo sentido de se obter um equilíbrio entre o interesse social e o interesse privado, entre o direito dos titulares da propriedade intelectual e a promoção tecnológica. Procedendo nesse raciocínio, a pesquisa recusou o que se poderia denominar de caráter anacrônico do modelo clássico de propriedade, seja como paradigma, seja como fonte dos direitos que envolvem tecnologia, assim como o vetusto e superado argumento liberal ou de uma suposta liberdade absoluta na condução ou do destino do conhecimento e da tecnologia na economia moderna, não obstante tal afirmação, por sinal, exorbite o objeto da pesquisa realizada. A essas premissas liberais e sem propósitos sociais é necessário assinalar que a Constituição da República afastou as dúvidas existentes para a sociedade brasileira relativamente aos resultados das pesquisas tecnológicas e sua correspondente tutela pelo regime da propriedade intelectual: deve ser observado o interesse social e o desenvolvimento tecnológico e econômico do País (art. $5^{\circ}$, XXIX).

O significado da propriedade intelectual nos estudos da transferência de tecnologia em geral, além disso, deve ser ressaltado e exaltado pelos estudiosos da transferência de biotecnologia. A despeito da presença de enfoques cognoscitivos distintos, foram os profissionais (propriedade intelectual) que tornaram possível a construção de uma grande estrutura teórica (da transferência de tecnologia), sem paralelo em seu dinamismo. E em sua classificação, elevaram os estudiosos da propriedade intelectual a figura o contrato para o campo mais fértil de aplicação da transferência de tecnologia. 
Duas premissas se fazem necessárias para os campos dispersos da transferência de tecnologia biológica. A primeira é que o significado dos trabalhos, apreciados por resultados práticos, para a transferência que gera tecnologia, não se aplica em correspondência absoluta à transferência de biotecnologia. É que o enfoque dinâmico da natureza e da vida estarão a exigir um verdadeiro sistema próprio para uma e para outra.

Sob um ponto de vista dinâmico, a formação dos elementos vivos, tais como os micro-organismos, que podem chegar às raias das teorias evolucionistas, não se coadunam com os elementos estáticos e sem vida que os mecanismos normais da transferência de tecnologia apresentam ou ordinariamente utilizam. Aqui, neste estudo, a vetusta distinção do que é estático e do que é dinâmico, parece ter uma aplicação direta e específica.

Esse enfoque estático-dinâmico é o ponto de partida para distinguir as reações biológicas da tecnologia aqui estudada daquelas outras que se ajustam com procedimentos que se complementam uns aos outros, tais como máquinas, matéria prima e eletricidade.

A transferência de biotecnologia ainda - ou talvez sempre! - exigirá riscos não conhecidos pela capacidade dos seres vivos de alterarem sua própria forma de ser e de sofrerem os influxos externos de temperatura e pressão. É por isso que a tentativa de abranger a biotecnologia pela tecnologia geral e a transferência biotecnológica pela tecnológica encontra limites. Assim, a influência da vitoriosa teoria das obrigações de resultado para os contratos de transferência de tecnologia não abriga os contatos de transferência de biotecnologia que continuarão a ser guardados pelo regime das obrigações de meio.

A elaboração de uma nova forma de conhecimento científico baseada em uma visão interdisciplinar do conhecimento biológico para o tecnológico poderia gerar um especial interesse de desmistificar a premissa fundamental elaborada por Tullio Ascarelli, de que haverá uma tutela para cada forma de manifestação da propriedade intelectual. Dessa forma, a 
Biotecnologia estaria a determinar um desvio em todo conhecimento construído em nosso País, baseado nos trabalhos de Tullio Ascarelli.

É a esse respeito que surge uma questão de importância excepcional sobre a relação entre formas de propriedade intelectual e a sua proteção ou tutela jurídica. A sucessão combinada de elementos químicos e biológicos não nos parece criar um novo regime de classificação científica da propriedade intelectual. A proposição de Tullio Ascarelli, se agrega mais uma vez sobre a propriedade industrial, por meio de uma compreensão própria: eles são isomórficos!

O isomorfismo será a fórmula de aplicação em correspondência biunívoca à Biotecnologia e à Química e à Farmacêutica, porque são estruturas complexas em suas entidades e que se aplicam umas às outras, indistintamente, como partes com um papel similar, nas respectivas estruturas. Não obstante a complexidade dos elementos biológicos, a afirmação de Tullio Ascarelli não se vê desconstituída pelos descobrimentos da Biotecnologia, mas se levanta com seus próprios pés.

Dito de outra maneira: o segredo do êxito das teorias desenvolvidas por Tullio Ascarelli está no fato de que ele captou corretamente a tutela de proteção da propriedade intelectual, sem prejuízo das complicações dos fenômenos estudados pelas distintas áreas do conhecimento e que sejam capazes de merecer uma proteção pela propriedade intelectual.

Assim se levam à conclusão as premissas da não aplicação da obrigação de resultado em correspondência da tecnologia geral transferida para a biotecnologia e a não-separação entre a obra de Ascarelli e Biotecnologia protegida e transferida. 


\section{BIBLIOGRAFIA}

ASCARELLI, Tullio. Teoria della concorrenza e dei beni immateriali.Istituzioni di Diritto Industriale. Milão: Giuffrè, 1960.

ASSAFIM, João Marcelo de Lima. A transferência de tecnologia no Brasil. Rio de Janeir: Lumen Juris, 2005.

BIZEC, René-François. Les transferts de technologie. Paris: PUF, 1981.

BOFF, Salete Oro; Pimentel, Luiz Otávio. Propriedade intelectual, gestão da inovação e desenvolvimento. Passo fundo: Imed, 2009.

CANARIS, Claus-Wilhelm. Pensamento sistemático e conceito de sistema na ciência do direito. $2^{\mathrm{a}}$ ed. Lisboa: Fundação Calouste Gulbenkian, 1996.

CARRASCO SOURÉ, Hugo. La propiedad intelectual y la investigación farmacêutica. México: Porrua, 2012.

CASTIGLIONE, Pietro. La tecnologia del Brasile. Pádua: Cedam, 1969.

COMTE, Auguste. La méthode positive en seize leçons. Paris: Vigot Freres, 1917

CORREA, Carlos M. Derechos de propiedad intelectual competência y protección del interéspúblico . Buenos Aires: Euros Editores, 2009.

DEL NERO, Patrícia Aurélia. Propriedade intelectual A tutela jurídica da biotecnologia. São Paulo: RT, 1998.

DIAZ, Álvaro. América Latina y el Caribe: La propiedad intelectual después de los tratados de libre comercio. Santiago: Cepal, 2008.

DELL'ANNO, Davide. La conoscenza dall'università all'impresa. Processi di trasferimento tecnologico e sviluppo locale. Roma: Carocci, 2010.

DEMOGUE, René. Traité des obligations en général. Paris: Librairie Arthur Rousseau, 1923.

DOMINGUES, Douglas Gabriel. Privilégios de invenção, engenharia genética e biotecnologia. Rio de Janeiro: Forense, 1989.

FLORES, César. Contratos internacionais de transferência de tecnologia. 
Rio de Janeiro: Lumen Juris, 2003.

GARCIA, Maria. Limites da ciência. São Paulo: RT, 2004.

GASSEN, Hans Günter. Biotecnologia em discussão. São Paulo: Fundação Konrad Adenauer, 2000.

GOMES, Orlando. Contratos. 20ª ed. Rio de Janeiro: Forense, 2000.

GONZÁLEZ, Maria Estrella L.; XAVIER FILHO, Lauro; CÓRDOBA, Carlos Vicente. Metabolitos vegetales y microbianos para la indústria un enfoque biotecnológico. Rio de Janeiro: Âmbito Cultural, 2008.

GRÜN, Ernesto. Una vision sistemica y cibernética del derecho. Buenos Aires: Abeledo-Perrot, 1995.

GUERRERO GAITÁN, Manuel. Los contratos de transferência internacional de tecnologia. Bogotá: Universidad Externato de Colômbia, 2014.

HESSEN, Johannes. Teoria do conhecimento. Trad. António Correia, Coimbra: Armênio Amado, 1980.

HOUGH, J.S. Biotecnología de la cerveza y de la malta. Zaragoza: Acribia, 1990.

HOSELITZ, Bert F. Aspectos sociológicos do crescimento. Rio de Janeiro: Fundo de Cultura, 1964.

HULL, L. W. H. Historia y Filosofia de la ciencia. Trad. Manuel Sacristán, Barcelona: Ariel, 1977,

IACOMINI, Vanessa. Propriedade intelectual e biotecnologia. Curitiba, Juruá, 2007.

JAGNOW, G.; DAWID, W. Biotecnología Introducción con experimentos modelo. Zaragoza: Acribia, 1991.

LARPENT, J. P. Biotechnologie des levures. Paris: Masson, 1991.

LE MOIGNE, Jean-Louis. A teoria do sistema geral. Trad. Jorge Pinheiro. Lisboa: Piaget, 1990.

LEONARDOS, Gabriel Francisco. Tributação da transferência de tecnologia. Rio de Janeiro: Forense, 1997.

LUHMANN, Niklas. Introdução à teoria dos sistemas. Trad. Petrópolis: 
Vozes, 2002.

MARTINE, George; Castro, Cláudio de M. Biotecnologia e sociedade: o caso brasileiro. São Paulo: Almed, 1985.

MARTÍNEZ, Gerson Elí; CASTRO BONILLA, Alejandro. Propiedad intelectual y acceso a medicamentos esenciales de calidad em Centroamérica. San Salvador: Funde, 2008.

MARTINS, Fran. Contratos e obrigações comerciais. $13^{\circ}$ ed. Rio de Janeiro: Forense, 1995.

MATHIEU, Vittorio. Crisi della tecnica. Roma: Dino Editore, 1999.

MATURANA, Humberto. A ontologia da realidade. Trad. Cristina Magro. Belo Horizonte: UFMG, 2002.

OLSCAMP, Paul. J. Introdução à Filosofia. Trad. Carlos Sebastião Mesquitella. Rio de Janeiro: Livros Técnicos e Científicos Editora S.A., 1980.

PALAZZOLO, Vincenzo. Scienza e epistemologia giuridica. Pádua: Cedam, 1957.

PALMA, G. A.; BREM, G. Transferencia de embriones y biotecnologia de la reproducción en la espécie bovina. Buenos Aires: Hemisferio Sur, 1993.

PEREIRA, Caio Mário da Silva. Instituições de Direito Civil. V. III.10a ed. Rio de Janeiro: Forense, 1995.

PANIKER, Raimundo. Ontonomia de la ciencia. Madri: Gredos, 1961.

PRADO, Maurício Curvelo de Almeida. Contrato internacional de transferência de tecnologia. Porto Alegre: Livraria do Advogado, 1997.

RIFKIN, Jeremy. O século da biotecnologia. São Paulo: Makron, 1999.

ROBLES, Gregorio. Epistemologia y derecho. Madri: Piramide, 1982.

SERAFINI, Luciana Atti; BARROS, Neiva Monteiro de; AZEVEDO, João Lúcio de. Biotecnologia: avanços na agricultura e na agroindústria. Caxias do Sul: EDUCS - Editora Universidade de Caxias do Sul, 2002.

SHERWOOD, Robert M. Propriedade intelectual e desenvolvimento econômico. São Paulo: Edusp, 1992. 
SILVA, Miguel Moura e. Inovação, transferência de tecnologia $e$ concorrência. Coimbra: Almedina, 2003.

SILVEIRA, Newton. Propriedade intelectual. $4^{\mathrm{a}}$ ed. São Paulo: Manole, 2011.

SOUZA JUNIOR, Sidney Pereira de. Patente de invenção em biotecnologia transgênica: exercício abusivo na agricultura. São Paulo: Verbatim, 2017.

STANZICK, Karl-Heinz; GODOY, Horacio H. Inversiones extranjeras y transferência de tecnologia en América Latina. Santiago de Chile: Editorial Universitaria, 1972.

STRENGER, Irineu. Marcas e patentes. $2^{\mathrm{a}}$ ed. São Paulo: LTr, 2004.

TABAK, Fanny. Dependência tecnológica e desenvolvimento nacional. Rio de Janeiro: Pallas, 1975.

TAVARES, Luiz Eduardo dos Santos. Prospecção, proteção \& transferência de tecnologia: um manual de propriedade intelectual. Fortaleza: EdUECE, 2012.

TREVAN, M. D. et alii. Biotecnologia: princípios biológicos. Zaragoza: Acribia, 1990.

VITOLO, Michele. Biotecnologia farmacêutica. São Paulo: Blucher, 2015.

VICENTE, Dario Moura et alii. Estudos de Direito Intelectual em homenagem ao Professor Doutor José de Oliveira Ascensão. Coimbra: Almedina, 2016.

WIONCZEK, Miguel S.: BUENO, Geraldo M.; NAVARRETE, Jorge Eduardo. La transferência internacional de tecnologia. México: Fondo de Cultura Económica, 1988.

YANCHINSKI, Stephanie. La revolucion biotecnologica. Madri: Debate, 1985.

ZANINI, Luciana Olivares; DELLAGOSTIN, Odir Antonio. Patentes: Um tutorial de propriedade intelectual para a biotecnologia. Lisboa: Chiado, 2015. 